\title{
Biportal endoscopic decompression vs. microscopic decompression for lumbar canal stenosis: A systematic review and meta-analysis
}

\author{
TIEWU CHEN ${ }^{1}$, GUOQING ZHOU ${ }^{1}$, ZHINENG CHEN $^{1}$, XINMIAO YAO ${ }^{1}$ and DAN LIU ${ }^{2}$ \\ ${ }^{1}$ Department of Traditional Chinese Orthopedics, The Third Affiliated Hospital of Zhejiang, \\ Chinese Medical University, Hangzhou, Zhejiang 310005; ${ }^{2}$ Department of General Surgery, \\ The Third People's Hospital of Hangzhou, Hangzhou, Zhejiang 310000, P.R. China
}

Received January 23, 2020; Accepted May 1, 2020

DOI: $10.3892 /$ etm.2020.9001

\begin{abstract}
Lumbar decompressive surgery is the gold standard treatment for lumbar spinal stenosis. Minimally invasive surgical techniques have been introduced with the aim of reducing the morbidity associated with open surgery. The purpose of the present study was to systematically search the literature and perform a meta-analysis of studies comparing the outcomes between biportal endoscopic technique and microscopic technique for lumbar canal stenosis decompression. A comprehensive search of the PubMed, Google Scholar, Web of Science, Embase and the Cochrane Library databases was performed to identify relevant articles up to 15th of December 2019. Eligible studies were retrieved, data were extracted by two authors independently and risks of bias were assessed. A total of six studies involving 438 patients were selected for review. The results of the pooled analysis indicated similar operative times [mean difference (MD), -3.41; 95\% CI, -10.78-3.96; $\mathrm{P}<0.36$ ], similar complications (MD, 0.70; 95\% CI, 0.33-1.46; $\mathrm{P}=0.34$ ), similar visual analogue scale scores for back and leg pain at the time of the final follow-up and similar Oswestry disability indexes (MD, $-0.28 ; 95 \% \mathrm{CI},-1.25-0.69 ; \mathrm{P}=0.58)$ for the two procedures. In conclusion, biportal endoscopic technique is a viable alternative to microscopic technique for lumbar canal stenosis decompression with similar operative time, clinical outcomes and complications.
\end{abstract}

\section{Introduction}

Lumbar canal stenosis, a degenerative condition commonly seen in older individuals, is characterized by pathological spinal canal narrowing and compression of the canal sac along

Correspondence to: Dr Dan Liu, Department of General Surgery, The Third People's Hospital of Hangzhou, 38 West Lake Avenue, Hangzhou, Zhejiang 310000, P.R. China

E-mail: ctw275ld@gmail.com

Key words: biportal endoscopic spinal surgery, lumbar spinal stenosis, degenerative spine, microscopy with the nerve roots (1). The usual clinical symptoms include lower backache, neurogenic claudication, lower limb pain and decreased walking ability. The disease not only affects daily function but also has a significant impact on the overall quality of life (2). Initial management usually consists of conservative measures, such as physiotherapy, steroid injections and oral medications $(2,3)$. However, in patients with incapacitating pain, gradually shortened walking distances, neurological deficit progression and failed conservative management, surgical treatment is usually recommended (3). Studies have indicated better clinical outcomes with surgical treatment than with conservative management $(3,4)$.

The primary aim of surgical treatment is to decompress the neural structures, thereby relieving symptoms and improving function (5). However, conventional open surgery requires extensive dissection and traction of paraspinal muscles that may lead to muscle ischemia and denervation resulting in atrophy, postoperative back pain and patient dissatisfaction $(5,6)$. To overcome these limitations, minimally-invasive techniques were developed. In such methods, arthroscopes, endoscopes or microscopes are introduced through small incisions, providing the operator with a clear working view with limited damage to adjacent structures (6). These techniques preserve posterior midline structures and achieve sufficient decompression by unilateral laminotomy and bilateral decompression (ULBD). Among the various minimally invasive methods, a biportal endoscopic approach is an emerging technique for managing disc herniation and lumbar canal stenosis (7). Unlike conventional spinal endoscopy, where the working as well as the visual channel are in a single portal, biportal endoscopic technique utilizes two portals, of which one is the endoscopic portal and the other is the working portal. Thus, the working instruments may be moved independently of the visualization portal offering a better range of motion and convenience to the operator $(7,8)$. The clear magnified view and free handling of tissues allow for safe and adequate neural decompression. Recent studies have demonstrated favorable results with a biportal endoscopic technique for the management of lumbar canal stenosis (7-9). However, to date, no meta-analysis has compared outcomes of lumbar canal stenosis decompression between biportal endoscopic and microscopic techniques. Therefore, the purpose of the present study was to systematically search the literature and perform 
a meta-analysis of studies comparing the outcomes between biportal endoscopic technique and microscopic technique for lumbar canal stenosis decompression.

\section{Data and methods}

Search strategy. The present meta-analysis was performed according to the methods described in the Preferred Reporting Items for Systematic reviews and Meta-Analysis statement (10). A total of two authors (GZ and ZC) independently searched the PubMed, Google Scholar, Web of Science, Embase and the Cochrane Library databases for relevant studies published in the English language from database inception to the 15th of December 2019. The following key words were used for the search: 'Lumbar canal stenosis', 'minimally invasive surgery', 'surgical decompression', 'endoscopy' and 'biportal technique'. The references within the included articles were also searched to identify additional relevant studies. A third reviewer (XY) was consulted to resolve any disagreements between the two authors performing the literature search.

Study selection. Studies were selected according to the Population, Intervention, Comparison and Outcomes criteria (11). Studies performed on patients with lumbar canal stenosis as the Population, comparing biportal endoscopy as the Intervention with microscopic endoscopy for Comparison, and assessing at least operating time or complications as Outcomes were included. Studies were excluded if they were: i) Single-arm studies without any comparative group, ii) studies not reporting relevant data or iii) case series, case reports and review articles.

Data extraction and review. Two authors (GZ and ZC) extracted data on study design, sample size, baseline features, intervention details and outcome variables. Any disagreements between the two authors were resolved through discussion with the third investigator (XY). The primary outcomes were operative time and complications. Secondary outcomes were hospital stay, Oswestry disability index (ODI) and pain measured on the visual analog score (VAS).

Quality assessment. The quality of studies that were not randomized controlled trials (RCTs) was assessed using the risk of bias assessment tool for non-randomized studies (12). Studies were rated as having a low risk, high risk or unclear risk of bias in the following categories: Selection of participants, confounding variables, measurement of exposure, blinding of outcome assessment, incomplete outcome data and selective outcome reporting. RCTs were assessed using the Cochrane Collaboration risk assessment tool for RCTs (13). Studies were rated as having low risk, high risk or unclear risk of bias in terms of the following points: Random sequence generation, allocation concealment, blinding of participants and personnel, blinding of outcome assessment, incomplete outcome data, selective reporting and other biases.

Statistical analysis. Statistical analyses were performed using Review Manager software (version 5.3; The Cochrane Collaboration). For categorical variables, data were

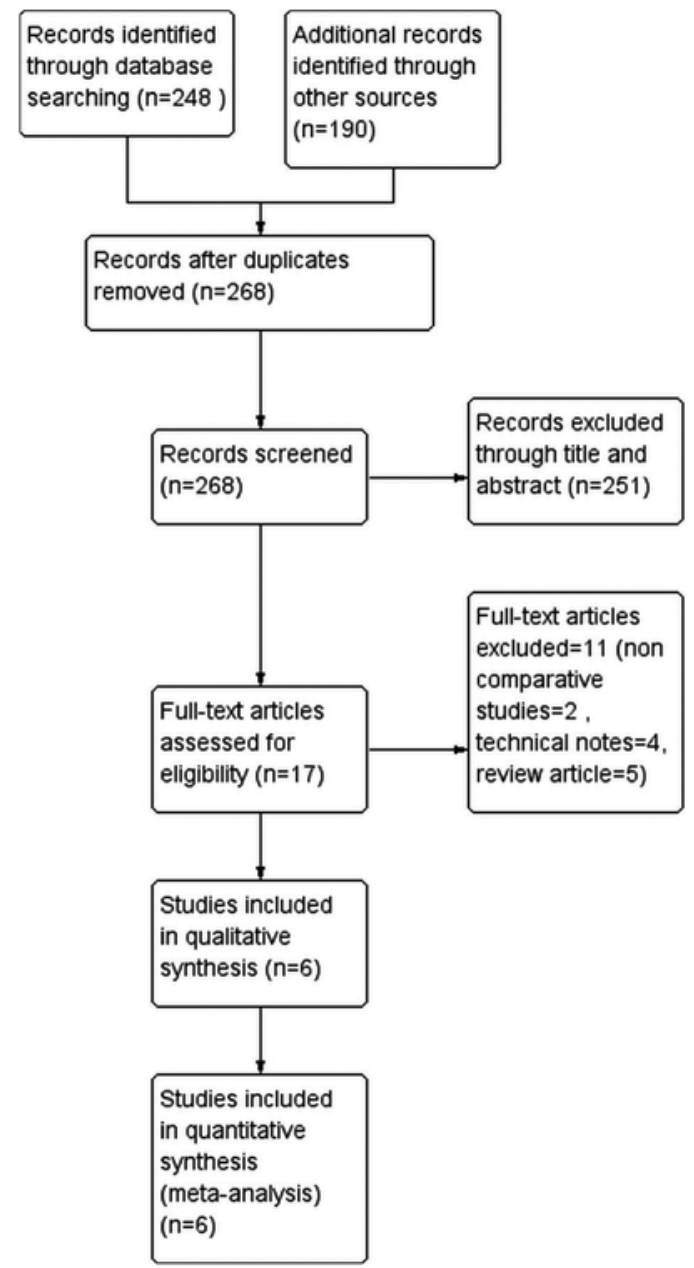

Figure 1. Flow diagram depicting the process of selection of studies for the present review and meta-analysis.

summarized using the Mantel-Haenszel odds ratio (OR) with 95\% CIs. Continuous data are presented as mean differences (MDs) and 95\% CI. The $\mathrm{I}_{2}$ test was used to assess statistical heterogeneity. $I_{2}$ values $\geq 50 \%$ were considered to indicate significant heterogeneity and a random-effect model was used for meta-analysis. However, if $\mathrm{I}_{2}$ was $<50 \%$, a fixed-effects model was used.

\section{Results}

Selection of studies and bias assessment. Details of the literature search for the present review are presented in Fig. 1. After excluding duplicates, 268 articles we screened based on the inclusion and exclusion criteria. After excluding non-relevant studies, 17 articles were screened by their full texts and 11 studies were excluded as they did not fulfill the inclusion criteria. Finally, 6 trials were included in the systematic review and meta-analysis (14-19). The risk of bias assessment of the included studies is presented in Table I. The overall quality of the RCTs was moderate-to-high. For non-RCTs, there was low risk of bias for 'selection of participants', 'incomplete outcome data' and 'selective outcome reporting' but a high risk of bias for 'blinding of outcome assessment' owing to their study designs. The only study that had low risk of bias for 'confounding factors' was that of Heo et al (18). 
Table I. Judgement of risk of bias in included studies.

A, RCTs

\begin{tabular}{|c|c|c|c|c|c|c|c|c|}
\hline Study & $\begin{array}{l}\text { Random } \\
\text { sequence } \\
\text { generation }\end{array}$ & $\begin{array}{c}\text { Allocation } \\
\text { concealment }\end{array}$ & $\begin{array}{c}\text { Blinding } \\
\text { of participants } \\
\text { and personnel }\end{array}$ & $\begin{array}{c}\text { Blinding } \\
\text { of outcome } \\
\text { assessment }\end{array}$ & $\begin{array}{c}\text { Incomplete } \\
\text { outcome } \\
\text { data }\end{array}$ & $\begin{array}{l}\text { Selective } \\
\text { reporting }\end{array}$ & $\begin{array}{l}\text { Other } \\
\text { biases }\end{array}$ & (Refs.) \\
\hline Kang (2019) & Low risk & Unclear risk & High risk & Low risk & Low risk & Unclear risk & Low risk & (16) \\
\hline Park (2020) & Low risk & Low risk & Low risk & Low risk & Low risk & Low risk & Low risk & (14) \\
\hline
\end{tabular}

B, Non-RCTs

\begin{tabular}{|c|c|c|c|c|c|c|c|}
\hline Study & $\begin{array}{c}\text { Selection } \\
\text { of participants }\end{array}$ & $\begin{array}{l}\text { Confounding } \\
\text { variables }\end{array}$ & $\begin{array}{l}\text { Measurement } \\
\text { of exposure }\end{array}$ & $\begin{array}{l}\text { Blinding } \\
\text { of outcome } \\
\text { assessment }\end{array}$ & $\begin{array}{c}\text { Incomplete } \\
\text { outcome } \\
\text { data }\end{array}$ & $\begin{array}{l}\text { Selective } \\
\text { reporting } \\
\text { outcome }\end{array}$ & (Refs.) \\
\hline Choi (2019) & Low risk & High risk & Unclear risk & High risk & Low risk & Low risk & (19) \\
\hline Heo (2018) & Low risk & Low risk & Low risk & High risk & Low risk & Low risk & (18) \\
\hline Heo (2019) & Low risk & High risk & Unclear risk & High risk & Low risk & Low risk & (17) \\
\hline Min (2019) & Low risk & Unclear risk & Low risk & High risk & Low risk & Low risk & (15) \\
\hline
\end{tabular}

RCT, randomized control trial.

Characteristics of included studies. Details of the studies included are presented in Table II. A total of 438 patients with lumbar canal stenosis were analyzed in the included studies, 233 of which underwent biportal endoscopic decompressions, while 200 patients underwent microscopic decompression. All studies were performed in Korea. With the exception of one study (19), all studies performed single-level surgeries.

Primary outcomes. A total of 5 studies (14-18) compared the operative time between biportal endoscopy and microscopic endoscopy. The results of the pooled analysis demonstrated no statistically significant differences between the biportal endoscopic and microscopic decompression groups (MD, -3.41; 95\% CI, -10.78-3.96; P=0.36; Fig. 2).

The total number of complications in each group was pooled for meta-analysis. The results indicated no statistically significant differences in complication rates between the two groups (OR, 0.70; 95\% CI, 0.33-1.46; P=0.34; Fig. 3). Details of complications in the included studies are presented in Table II.

Secondary outcomes. A total of 5 studies (14,15,17-19) reported on back pain VAS scores at the final follow-ups. The pooled analysis demonstrated no statistically significant difference in back pain scores between the two groups (MD, -0.17; 95\% CI, -0.3-0.02; P=0.09; Fig. 4). Data on leg pain VAS scores were reported by 5 studies $(14,15,17-19)$. The meta-analysis demonstrated no statistically significant differences in leg pain scores between the two groups at the final follow-ups (MD, -0.09 ; $95 \% \mathrm{CI},-0.27$ to 0.09 ; $\mathrm{P}=0.35$; Fig. 5).

A total of 4 studies $(14,15,17,18)$ reported data on the ODI scores at the final follow-ups. Meta-analysis indicated no statistically significant difference between the biportal endoscopic decompression and microscopic decompression groups (MD, -0.28; 95\% CI, -1.25-0.69; P=0.58; Fig. 6). Data on the length of hospital stay were pooled from two studies $(15,16)$. The analysis indicated a significantly shorter length of hospital stay in the biportal group (MD, $-2.60 ; 95 \% \mathrm{CI},-3.39$ to -1.81 ; $\mathrm{P}<0.00001$; Fig. 7).

\section{Discussion}

In the present meta-analysis, the comparison of the outcomes of biportal endoscopic technique and the microscopic technique indicated that the two techniques may be equally suitable for managing lumbar canal stenosis. No significant difference in operative times, complication rates, back pain and leg pain VAS scores or ODI scores were identified between the two groups.

A number of different minimally-invasive techniques have been reported for lumbar degenerative disease $(20,21)$. The advantage of minimally invasive surgery lies in the preservation of normal anatomical structures, leading to faster post-operative recovery (21). Several studies comparing the microscopic ULBD technique with open surgery have reported favorable outcomes with the former $(22,23)$. Trials have reported shorter operating times, reduced blood loss, shorter hospital stay and fewer complications with ULBD technique as compared to open surgery $(22,24)$. However, there are certain limitations to the microscopic technique. First, instrument manipulation is difficult due to the use of a single port. Second, while contralateral visualization may be achieved, the microscope requires to be excessively tilted in certain cases $(15,25)$. In addition, there have been concerns regarding inadequate exposure with the microscope, which may lead to unsatisfactory decompression $(23,26)$. The technique is also associated with a steep learning curve, which may prolong the operative time in the hands of a novice surgeon (27). 


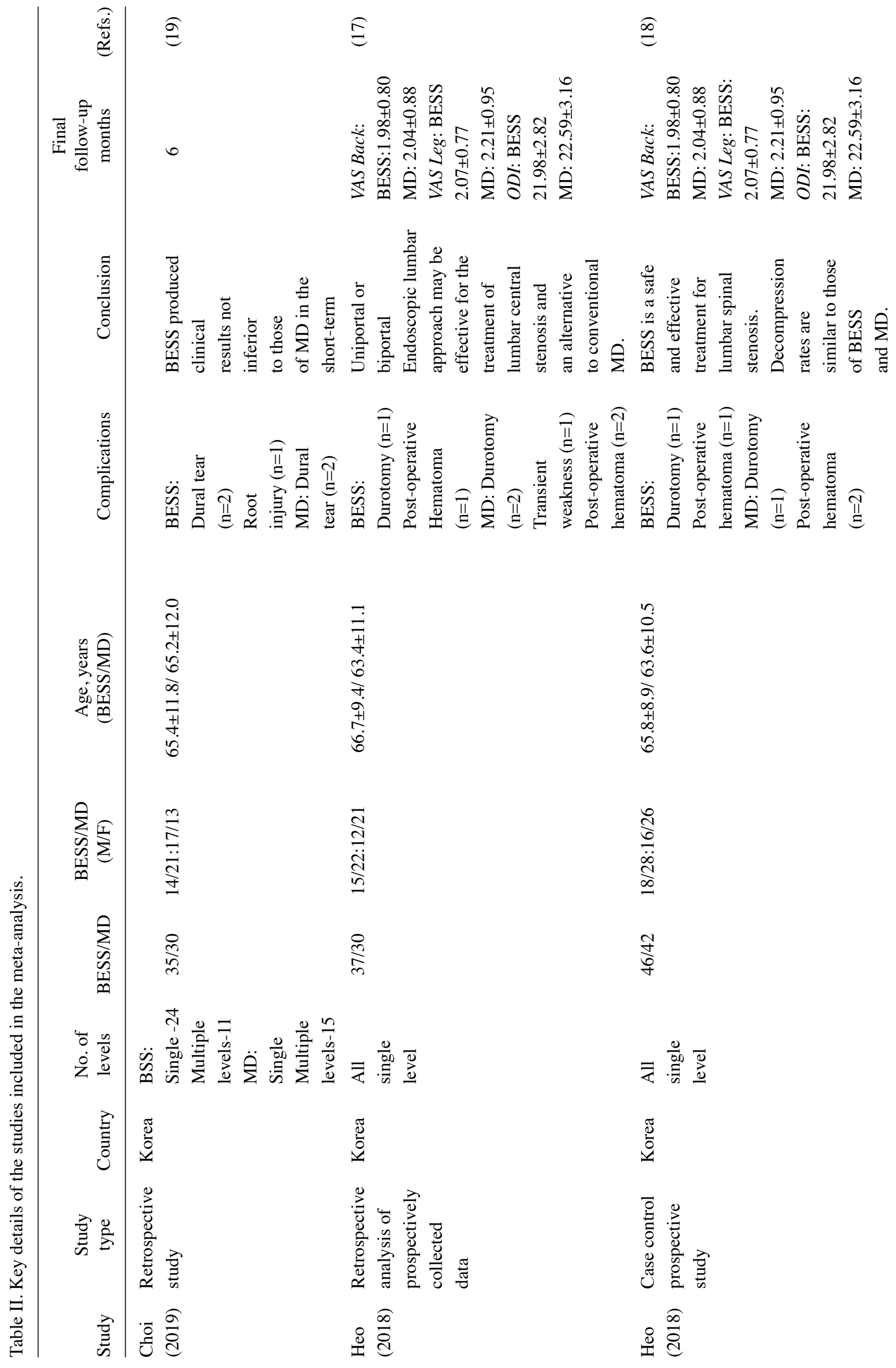




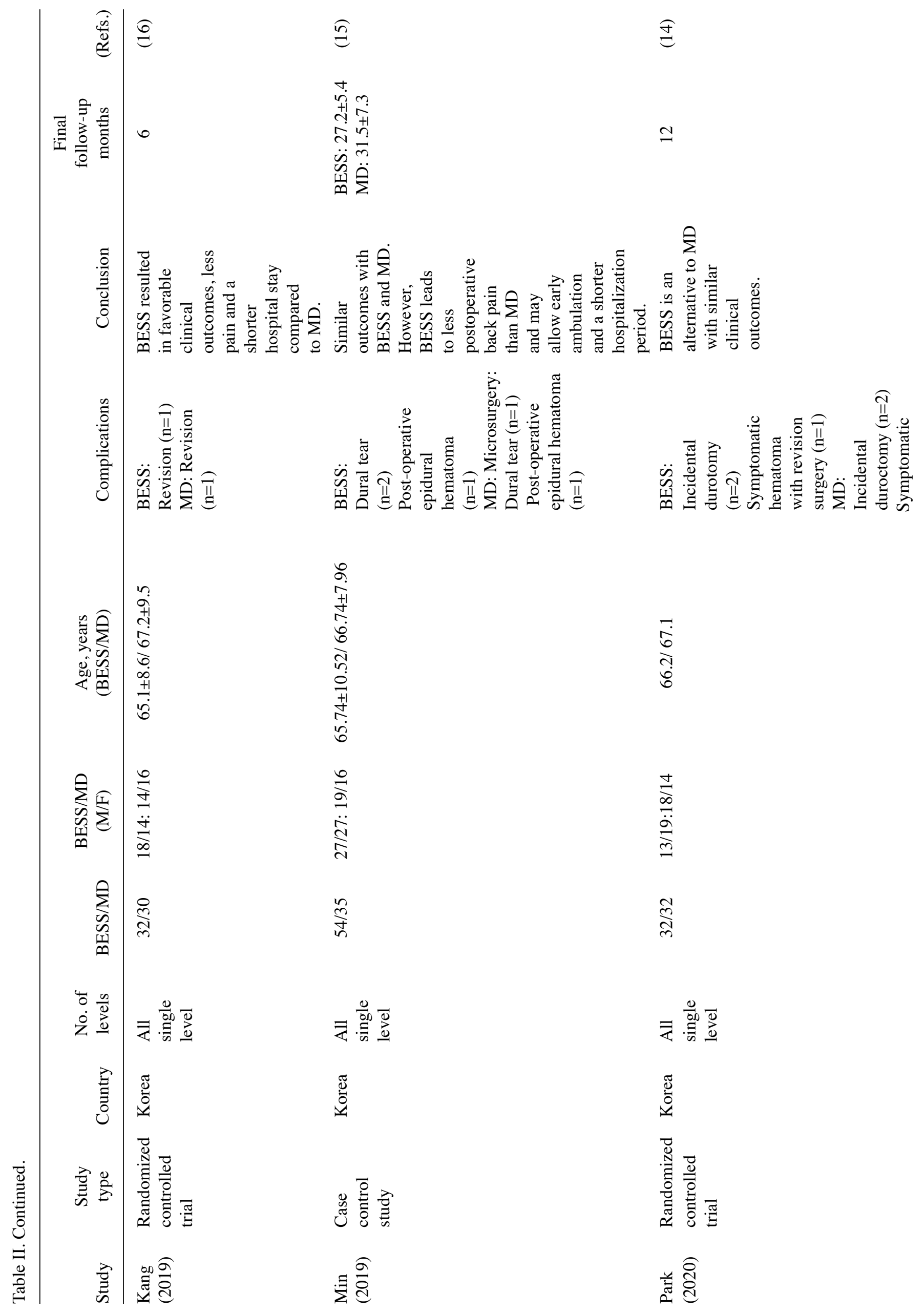


In recent times, endoscopic decompression has been introduced to manage patients with lumbar stenosis (28). However, the requirement for specialized instruments and extensive training to reach surgical competency is a disadvantage (29). On the other hand, the instruments used in the biportal technique are the same as those used for knee arthroscopies and conventional spine surgeries, which may potentially reduce hospital costs $(14,30)$. As biportal endoscopic technique shares the principles of arthroscopy, the learning curve is thought to be comparable with that of microscopic methods (17). According to Heo et al (17), around 30 operations under supervision are required to complete the learning curve associated with this technique. In addition, the field of view provided by the biportal technique is wider than that of single-port endoscopes and is comparable to the view offered by a microscope (14). The separation of viewing and working portals in the biportal technique enable the surgeon to use both hands freely, making instrument manipulation easier as compared to the uniportal or microscopic technique. The contralateral sublaminar and foraminal spaces may be visualized more conveniently, particularly with the use of a $30^{\circ}$ endoscope (31). However, pooled analysis of 5 studies did not identify any significant differences in operating times as compared with the biportal and the microscopic technique. The operative time was significantly shorter with the biportal technique as compared to microscopic technique in a study by Kang et al (16). The authors reported that with the biportal technique, the use of fluoroscopy may be avoided after the preoperative level check, which saves time. Furthermore, the clear and wide visualization provided by the biportal technique and free movement of instruments may also contribute to reduced operative time.

In the present analysis, no significant difference in ODI scores and VAS scores for back pain and leg pain was identified between the two groups. In this context, a study has reported lower opioid use in the early postoperative period in patients undergoing surgery with the biportal technique as compared to the microscopic technique (31). In addition, Choi and Kim (19) reported a lower postoperative elevation of $\mathrm{C}$-reactive protein (CRP) in patients undergoing endoscopic procedures in comparison with the microscopic procedures. The authors suggested that lower CRP levels may indicate reduced muscle injury and better irrigation with the biportal technique. On the other hand, Park et al (14) did not obtain any statistically significant difference in serum creatine phosphokinase levels between the two groups. According to the authors, even the biportal technique requires a small incision and muscle stripping during the procedure, which is sufficient to elevate serum creatine phosphokinase levels. While both techniques require minimal soft-tissue dissection, there may be concerns regarding the persistence of symptoms with minimally invasive procedures due to inadequate decompression (15). However, the lack of differences in VAS and ODI scores in the present analysis indicates that both the biportal and microscopic technique result in similar outcomes.

In the present analysis, patients in the biportal group had a significantly reduced hospital stay than those in the microscopic technique group. However, the results must be interpreted with caution, as only two studies reported data on the length of hospital stay. In addition, the length of hospital stay may be confounded by numerous other factors, including 


\begin{tabular}{|c|c|c|c|c|c|c|c|c|c|c|c|c|}
\hline Study or Subgroup & \multicolumn{3}{|c|}{ Biportal endoscopic } & \multicolumn{3}{|c|}{ Microscopic } & Weight & $\begin{array}{l}\text { Mean Difference } \\
\text { IV, Random, 95\% CI }\end{array}$ & \multicolumn{3}{|c|}{$\begin{array}{c}\text { Mean Difference } \\
\text { IV, Random, } 95 \% \mathrm{CI}\end{array}$} & \\
\hline Heo (2018) & 61.1 & 5.2 & 46 & 58.9 & 6.9 & 42 & $21.6 \%$ & $2.20[-0.37,4.77]$ & \multicolumn{4}{|c|}{$=$} \\
\hline Heo (2019) & 62.4 & 5.7 & 37 & 56.4 & 4.7 & 33 & $21.6 \%$ & $6.00[3.56,8.44]$ & \multirow{2}{*}{\multicolumn{2}{|c|}{$\varpi$}} & $=$ & \\
\hline Kang (2019) & 36 & 11 & 32 & 54 & 9 & 30 & $20.1 \%$ & $-18.00[-22.99,-13.01]$ & & & & \\
\hline Min (2019) & 53.68 & 6.75 & 54 & 58.85 & 7.48 & 35 & $21.3 \%$ & $-5.17[-8.23,-2.11]$ & \multirow{2}{*}{\multicolumn{2}{|c|}{$=$}} & & \\
\hline Park (2020) & 67.2 & 19.8 & 32 & 70.2 & 22.8 & 32 & $15.3 \%$ & $-3.00[-13.46,7.46]$ & & & - & \\
\hline Total $(95 \% \mathrm{Cl})$ & \multicolumn{3}{|r|}{201} & & & 172 & $100.0 \%$ & $-3.41[-10.78,3.96]$ & & & & \\
\hline \multicolumn{9}{|c|}{$\begin{array}{l}\text { Heterogeneity: } \mathrm{Tau}^{2}=63.75 ; \mathrm{Chi}^{2}=87.31, \mathrm{df}=4(\mathrm{P}<0.00001) ; \mathrm{I}^{2}=95 \% \\
\text { Test for overall effect: } Z=0.91(P=0.36)\end{array}$} & -50 & $\begin{array}{l}-25 \\
\text { ours Biportal }\end{array}$ & Favours $\mathrm{Mi}$ & \\
\hline
\end{tabular}

Figure 2. Forest plot of operation times for the biportal endoscopic vs. microscopic technique. Green symbols indicate the mean difference. Horizontal lines indicate $95 \%$ confidence intervals. The black diamond indicates the overall effect size. SD, standard deviation; IV, inverse variance; df, degrees of freedom.

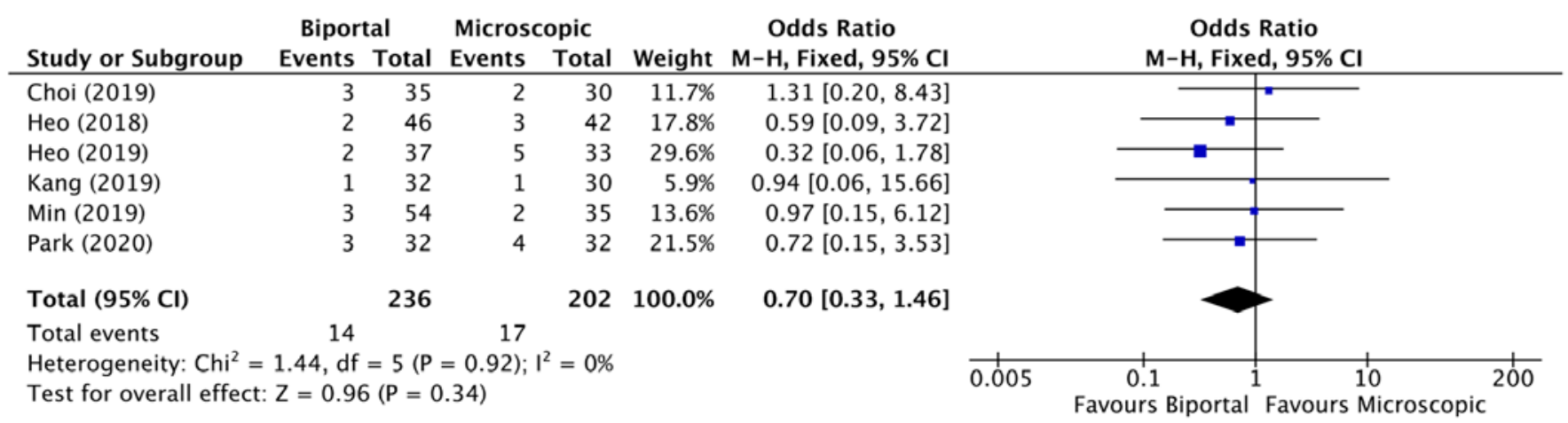

Figure 3. Forest plot of complications associated with the biportal endoscopic vs. microscopic technique. Blue symbols indicate odds ratios. Horizontal lines indicate $95 \%$ confidence intervals. The black diamond indicates the overall effect size. M-H, Mantel-Haentzel; df, degrees of freedom.

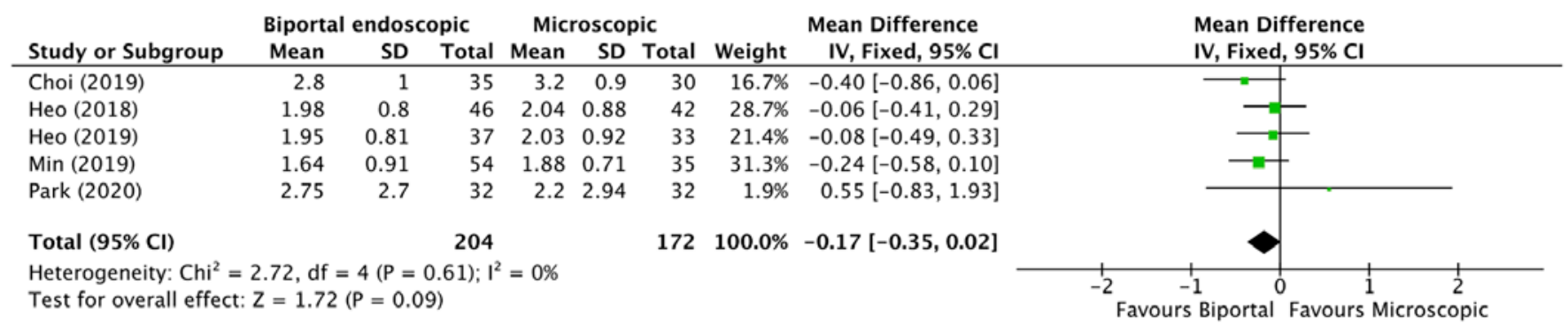

Figure 4. Forest plot of back pain visual analogue scale scores for the biportal endoscopic vs. microscopic technique at the final follow-up. Green symbols indicate the mean difference. Horizontal lines indicate 95\% confidence intervals. The black diamond indicates the overall effect size. SD, standard deviation; $\mathrm{IV}$, inverse variance; df, degrees of freedom.

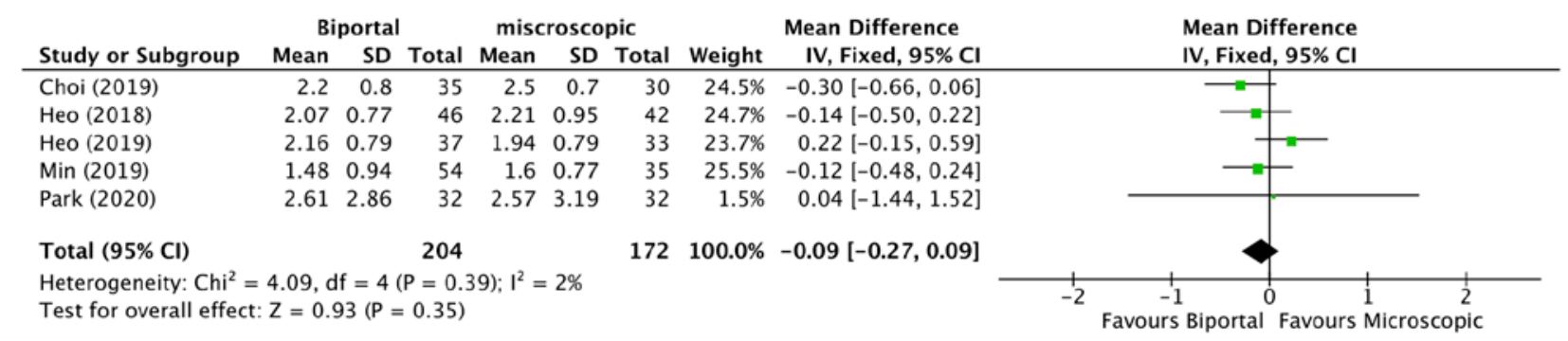

Figure 5. Forest plot of leg pain visual analogue scale scores for the biportal endoscopic vs. microscopic technique at the final follow-up. Green symbols indicate mean differences. Horizontal lines indicate $95 \%$ confidence intervals. The black diamond indicates the overall effect size. SD, standard deviation; $\mathrm{IV}$, inverse variance; df, degrees of freedom.

patient co-morbidity, complications with the procedure and local hospital protocols.
The complication rate of the biportal technique in the present analysis was $5.9 \%$, while that of the microscopic 


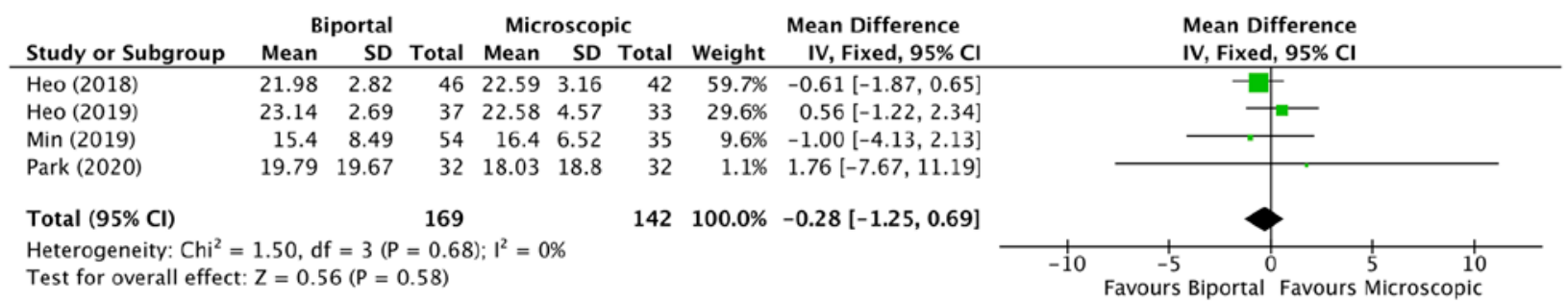

Figure 6. Forest plot of Oswestry disability indexes for the endoscopic vs. microscopic technique at the final follow-up. Green symbols indicate the mean difference. Horizontal lines indicate $95 \%$ confidence intervals. The black diamond indicates the overall effect size. SD, standard deviation; IV, inverse variance; df, degrees of freedom.

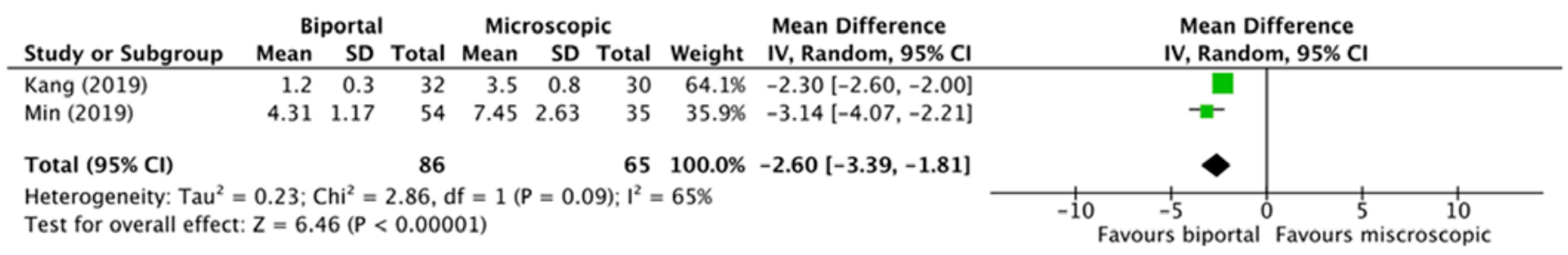

Figure 7. Forest plot of lengths of hospital stay for the endoscopic vs. microscopic technique. Green symbols indicate the mean difference. Horizontal lines indicate $95 \%$ confidence intervals. The black diamond indicates the overall effect size. SD, standard deviation; IV, inverse variance; df, degrees of freedom.

method was $8.4 \%$ with no statistically significant difference. Complication rates may be higher during the learning phase of minimally invasive procedures and adequate supervision is highly recommended (17). Furthermore, complications are higher when the surgical field is unclear due to bleeding (9). Bleeding with the biportal technique may be minimized by utilizing the high magnification of the surgical field along with continuous saline irrigation. While continuous irrigation reduces bleeding and keeps the surgical field clean, high-pressure irrigation is not recommended, as it may lead to increased intracranial pressure and delay postoperative recovery (32). A saline pressure at $30 \mathrm{mmHg}$ usually maintains a clear surgical field and causes minimal compression of the thecal sac, avoiding potential iatrogenic damage (32).

The limitations of the present study require to be acknowledged. First, only 6 studies were included in the present analysis, of which there were only two RCTs. The inherent bias of non-RCTs may have skewed the results. Furthermore, the sample size of the included studies was not large. In addition, there was no consistency in the results of the included studies, indicating high variability of the outcomes. Finally, the influence of the surgical experience of the operators on the study outcomes cannot be neglected. The difference in operative techniques and surgical skills may have influenced the outcomes.

To conclude, the present study indicates that the biportal endoscopic and microscopic techniques for lumbar canal stenosis decompression do not differ in terms of operative time, clinical outcomes and complications. The biportal endoscopic technique may be considered as an alternative to the microscopic decompression technique. However, further well-designed RCTs with larger sample size are required to strengthen the current evidence.

\section{Acknowledgements}

Not applicable.

\section{Funding}

This research was supported by The 6th Zhejiang Province National Traditional Chinese Medicine Experts Academic Experience Inheritance Project (grant no. 2018LPS07).

\section{Availability of data and materials}

The datasets used and/or analyzed during the current study are available from the corresponding author on reasonable request.

\section{Authors' contributions}

TC and DL designed the study. GZ, ZC and XY were involved in the literature search and data interpretation. TC, GZ and $\mathrm{ZC}$ were responsible for the data analysis. TC prepared the manuscript. DL edited the manuscript. All authors have read and approved the final manuscript.

\section{Ethics approval and consent to participate}

Not applicable.

\section{Patient consent for publication}

Not applicable.

\section{Competing interests}

The authors declare that they have no competing interests.

\section{References}

1. Hall S, Bartleson JD, Onofrio BM, Baker HL Jr, Okazaki H, O'Duffy JD: Lumbar spinal stenosis. Clinical features, diagnostic procedures, and results of surgical treatment in 68 patients. Ann Intern Med 103: 271-275, 1985. 
2. Parker SL, Godil SS, Mendenhall SK, Zuckerman SL, Shau DN and McGirt MJ: Two-year comprehensive medical management of degenerative lumbar spine disease (lumbar spondylolisthesis, stenosis, or disc herniation): a value analysis of cost, pain, disability, and quality of life: clinical article. J Neurosurg Spine 21: 143-149, 2014

3. Weinstein JN, Tosteson TD, Lurie JD, Tosteson AN, Blood E, Hanscom B, Herkowitz H, Cammisa F, Albert T, Boden SD, et al; SPORT Investigators: Surgical versus nonsurgical therapy for lumbar spinal stenosis. N Engl J Med 358: 794-810, 2008.

4. Malmivaara A, Slätis $P$, Heliövaara $M$, Sainio $P$, Kinnunen $H$, Kankare J, Dalin-Hirvonen N, Seitsalo S, Herno A Kortekangas P, et al; Finnish Lumbar Spinal Research Group: Surgical or nonoperative treatment for lumbar spinal stenosis? A randomized controlled trial. Spine 32: 1-8, 2007.

5. Ikuta K, Tono O, Tanaka T, Arima J, Nakano S, Sasaki K and Oga M: Surgical complications of microendoscopic procedures for lumbar spinal stenosis. Minim Invasive Neurosurg 50 145-149, 2007

6. Yagi M, Okada E, Ninomiya K and Kihara M: Postoperative outcome after modified unilateral-approach microendoscopic midline decompression for degenerative spinal stenosis. J Neurosurg Spine 10: 293-299, 2009.

7. Eun SS, Eum JH, Lee SH and Sabal LA: Biportal Endoscopic Lumbar Decompression for Lumbar Disk Herniation and Spinal Canal Stenosis: A Technical Note. J Neurol Surg A Cent Eur Neurosurg 78: 390-396, 2017.

8. Heo DH, Son SK, Eum JH and Park CK: Fully endoscopic lumbar interbody fusion using a percutaneous unilateral biporta endoscopic technique: Technical note and preliminary clinical results. Neurosurg Focus 43: E8, 2017.

9. Kim JE and Choi DJ: Unilateral biportal endoscopic decompression by $30^{\circ}$ endoscopy in lumbar spinal stenosis: Technical note and preliminary report. J Orthop 15: 366-371, 2018.

10. Moher D, Liberati A, Tetzlaff J and Altman DG; PRISMA Group: Preferred reporting items for systematic reviews and meta-analyses: The PRISMA statement. PLoS Med 6: e1000097, 2009.

11. Schardt C, Adams MB, Owens T, Keitz S and Fontelo P Utilization of the PICO framework to improve searching PubMed for clinical questions. BMC Med Inform Decis Mak 7: 16, 2007.

12. Kim SY, Park JE, Lee YJ, Seo HJ, Sheen SS, Hahn S, Jang BH and Son HJ: Testing a tool for assessing the risk of bias for nonrandomized studies showed moderate reliability and promising validity. J Clin Epidemiol 66: 408-414, 2013.

13. Higgins J, Thomas J, Chandler J, Cumpston M, Li T, Page M and Welch V: Cochrane Handbook for Systemic Reviews of Interventions. Version 6. Cochrane, 2019. https://doi. org/10.1002/9781119536604

14. Park SM, Park J, Jang HS, Heo YW, Han H, Kim HJ, Chang BS Lee CK and Yeom JS: Biportal endoscopic versus microscopic lumbar decompressive laminectomy in patients with spinal stenosis: A randomized controlled trial. Spine J 20: 156-165, 2020 .

15. Min W-K, Kim JE, Choi DJ, Park EJ and Heo J: Clinical and radiological outcomes between biportal endoscopic decompression and microscopic decompression in lumbar spinal stenosis. J Orthop Sci, 2019.

16. Kang T, Park SY, Kang CH, Lee SH, Park JH and Suh SW: Is biportal technique/endoscopic spinal surgery satisfactory for lumbar spinal stenosis patients?: A prospective randomized comparative study. Medicine (Baltimore) 98: e15451, 2019.

17. Heo DH, Lee DC and Park CK: Comparative analysis of three types of minimally invasive decompressive surgery for lumbar central stenosis: Biportal endoscopy, uniportal endoscopy, and microsurgery. Neurosurg Focus 46: E9, 2019.
18. Heo DH, Quillo-Olvera J and Park CK: Can percutaneous biportal endoscopic surgery achieve enough canal decompression for degenerative lumbar stenosis? Prospective case-control study. World Neurosurg 120: e684-e689, 2018.

19. Choi DJ and Kim JE: Efficacy of Biportal Endoscopic Spine Surgery for Lumbar Spinal Stenosis. Clin Orthop Surg 11: 82-88, 2019.

20. Storzer B and Schnake KJ: Microscopic bilateral decompression by unilateral approach in spinal stenosis. Eur Spine J 25 (Suppl 2): 270-271, 2016.

21. Alimi M, Hofstetter CP, Pyo SY, Paulo D and Härtl R: Minimally invasive laminectomy for lumbar spinal stenosis in patients with and without preoperative spondylolisthesis: Clinical outcome and reoperation rates. J Neurosurg Spine 22: 339-352, 2015.

22. Rahman M, Summers LE, Richter B, Mimran RI and Jacob RP: Comparison of techniques for decompressive lumbar laminectomy: The minimally invasive versus the 'classic' open approach. Minim Invasive Neurosurg 51: 100-105, 2008.

23. Phan K and Mobbs RJ: Minimally invasive versus open laminectomy for lumbar stenosis: A systematic review and meta-analysis. Spine 41: E91-E100, 2016.

24. Palmer S, Turner R and Palmer R: Bilateral decompression of lumbar spinal stenosis involving a unilateral approach with microscope and tubular retractor system. J Neurosurg 97: 213-217, 2002.

25. Thomé C,Zevgaridis D,Leheta O,Bäzner H,Pöckler-Schöniger C, Wöhrle J and Schmiedek P: Outcome after less-invasive decompression of lumbar spinal stenosis: A randomized comparison of unilateral laminotomy, bilateral laminotomy, and laminectomy. J Neurosurg Spine 3: 129-141, 2005.

26. Knotkova H, Fine PG and Portenoy RK: Opioid rotation: The science and the limitations of the equianalgesic dose table. J Pain Symptom Manage 38: 426-439, 2009.

27. Parikh K, Tomasino A, Knopman J, Boockvar J and Härtl R: Operative results and learning curve: Microscope-assisted tubular microsurgery for 1- and 2-level discectomies and laminectomies. Neurosurg Focus 25: E14, 2008.

28. Polikandriotis JA, Hudak EM and Perry MW: Minimally invasive surgery through endoscopic laminotomy and foraminotomy for the treatment of lumbar spinal stenosis. J Orthop 10: 13-16, 2013

29. Tenenbaum S, Arzi H, Herman A, Friedlander A, Levinkopf M, Arnold PM and Caspi I: Percutaneous posterolateral transforaminal endoscopic discectomy: Clinical outcome, complications, and learning curve evaluation. Surg Technol Int 21: 278-283, 2011.

30. Torudom Y and Dilokhuttakarn T: Two portal percutaneous endoscopic decompression for lumbar spinal stenosis: Preliminary study. Asian Spine J 10: 335-342, 2016.

31. Park SM, Kim GU, Kim HJ, Choi JH, Chang BS, Lee CK and Yeom JS: Is the use of a unilateral biportal endoscopic approach associated with rapid recovery after lumbar decompressive laminectomy? A preliminary analysis of a prospective randomized controlled trial. World Neurosurg 128: e709-e718, 2019.

32. Choi DJ, Choi CM, Jung JT, Lee SJ and Kim YS: Learning curve associated with complications in biportal endoscopic spinal surgery: Challenges and strategies. Asian Spine J 10: 624-629, 2016.

This work is licensed under a Creative Commons Attribution-NonCommercial-NoDerivatives 4.0 International (CC BY-NC-ND 4.0) License. 